\title{
DETECCIÓN DE RESIDUOS DE ANTIBIÓTICOS $\beta$-LACTÁMICOS Y TETRACICLINAS EN LECHE CRUDA COMERCIALIZADA EN EL CALLAO
}

\author{
Detection of residues of $\beta$-lactamic antibiotics and tetracyclines in raw milk marketed in Callao \\ Dániza M. Guerrero A ${ }^{1}$, Rodrigo Motta G², Gerardo Gamarra B ${ }^{3}$, Elena R. Benavides R ${ }^{3}$, Mirtha Roque A³ y María E. Salazar S 3 . \\ ${ }^{1}$ Facultad de Ingeniería Pesquera y de Alimentos - UNAC, ${ }^{2}$ Facultad de Medicina Humana - URP, ${ }^{3}$ Facultad de Farmacia y \\ Bioquímica - UNMSM.
}

\section{RESUMEN}

Se analizaron cuarenta muestras de leche cruda comercializada en mercados del distrito del Callao, entre enero y marzo del 2009, empleando el método presuntivo para antibióticos $\beta$-lactámicos y tetraciclinas de IDEX Laboratories, el cual cumple con los límites de sensibilidad de residuos de la FDA. Se encontró 40\% de muestras con resultado positivo para residuos de $\beta$-lactámicos en leche cruda. No se registran resultados positivos al analizar tetraciclinas. Los resultados sugieren que se deberían establecer políticas de legislación, regulación y capacitación, y que la NTP 202.001.2003 debería ser revisada.

Palabras clave: Leche cruda, residuos de antibióticos $\beta$-lactámicos y tetraciclinas.

\section{SUMMARY}

We are analyzed forty samples of raw milk commercialized at the Callao Market between January and March 2009 using presumptive method for $\beta$-lactamics and tetracycline antibiotic residues from IDEX laboratories, to comply with the limits of sensitivity of residues of the FDA. We found $40 \%$ of samples tested positive for $\beta$-lactamic residues in raw milk. There were no positive outcame to analyze tetracyclines. The results suggest that we should establish policies for legislation, regulation and training and that the NTP 202.001.2003 should be reviewed. The results suggested that should be established policies for legislation, regulation and training, and the NTP 202. 00102003 should be reviewed.

Keywords: Raw milk, $\beta$-latamic and tetracycline antibiotic residues.

\section{INTRODUCCIÓN}

$\mathrm{E}$ 1 término "antibiótico" se restringe a compuestos químicos producidos por microorganismos que tienen la capacidad de inhibir el crecimiento o destruir bacterias u otros microorganismos, incluyendo compuestos antimicrobianos obtenidos por síntesis. Actualmente esta distinción es más bien académica, ya que la palabra antibiótico se emplea para incluir ambos grupos de agentes antimicrobianos $^{(1)}$. Los antibióticos $\beta$-lactámicos inhiben la síntesis de la pared bacteriana constituida por peptidoglucanos. El sitio de acción de estos antibióticos es la muramoilpentapéptido carboxipeptidasa, enzima indispensable para el entrecruzamiento de la pared celular bacteriana ${ }^{(2)}$. Su consumo puede producir reacciones adversas como: erupciones maculopapulares, urticariana, fiebre, broncoespasmo, vasculitis, enfermedad del suero, dermatitis exfoliativa, síndrome de Stevens-Johnson y anafilaxia.
Las tetraciclinas tienen como punto de ataque los ribosomas bacterianos. Ejercen su efecto sobre un número grande de bacterias gram positivas y negativas, aerobias y anaerobias, micoplasmas, ricketsias, clamidias y espiroquetas. Frecuentemente originan resistencia. Las reacciones adversas consisten en irritaciones digestivas por administración oral: molestia por dolor epigástrico y abdominal, náuseas, vómitos y diarreas. También pueden producir en el ser humano fotosensibilidad por exposición cutánea al sol, toxicidad hepática o renal. En niños que reciben dosis elevadas por períodos de tiempo corto o largo pueden producir manchas oscuras en los dientes. Es posible que deprima el crecimiento óseo en lactantes prematuros, con efecto reversible si la exposición fue breve ${ }^{(3)}$.

La leche posee inhibidores naturales, tal es el caso de las lacteninas, inmunoglobulinas, pseudoglobulinas, ácidos grasos libres y leucocitos; sin embargo, la detección de inhibidores se efectúa mediante el análisis de residuos de antibióticos. 
En el hato lechero, la infección que demanda mayor suministro de antibióticos es la mastitis, y debido a que los antibióticos de uso intramamario son de fácil aplicación y generalmente baratos, no se hace la consulta respectiva al médico veterinario, constituyéndose en la principal causa de aparición de residuos de antibióticos en la leche. Al ganadero le es muy difícil eliminar leche producida por vacas con tratamiento por mastitis, pues le representa pérdida económica, por ello incurre en la práctica inadecuada de comercializarla derivándola a la industria de leche fluida pasteurizada o esterilizada y a los mercados como leche cruda o en mezcla con leches de buena calidad, para que no sea posible detectarla y que sus deficiencias pasen desapercibidas.

La presencia de residuos de antibióticos en la leche es considerada ilegal ${ }^{(4)}$ y reduce la producción de acidez y aroma durante la manufactura de la mantequilla y el yogurt ${ }^{(5)}$. Además, dificultan la maduración de los quesos por disminuir la retención de agua, originando textura blanda y sabor amargo. Las bacterias empleadas en la fabricación de yogurt resultan ser muy sensibles a los antibióticos, presentan cambios morfológicos y pueden darse situaciones en que los cultivos iniciadores sean reemplazados por microorganismos indeseables, provocando la inutilización del producto o que se convierta en peligroso para el consumo hu$\operatorname{mano}^{(6)}$.

Por muchos años la prueba estándar de uso regulatorio para la determinación de antibióticos ha sido la prueba del disco con Bacillus stearothermophilus ${ }^{(7)}$.

Actualmente los métodos desarrollados se clasifican en métodos presuntivos y de confirmación. Los presuntivos tienen como objetivo detectar la presencia de uno o varios residuos de antibióticos en una muestra sospechosa. Se considera en este grupo los métodos de inmunoensayo y los microbiológicos de ensayo receptor, en el que el analito se une al receptor, siendo el modo de detección el colorimétrico. Los de confirmación pueden emplear cromatografía líquida de alta performance, cromatografía líquida/espectrofotometría de masa y espectrofotometría de masa; estas metodologías son recomendadas por su elevada capacidad de cuantificación, especificidad y sensibilidad ${ }^{(8)}$.

Debido a las repercusiones para la salud de la población con menor poder adquisitivo y que consume habitualmente leche cruda por su menor costo, se planteó la necesidad de detectar la posible presencia de residuos de antibióticos $\beta$-lactámicos y tetraciclinas en leche cruda comercializada en el mercado del dis- trito del Callao.

\section{MATERIALES Y MÉTODOS}

Cada una de las 40 muestras fueron tomadas, de acuerdo a la norma correspondiente ${ }^{(9)}$, del contenedor en la que se comercializa la leche en el mercado del distrito del Callao, en envase de vidrio de un litro de capacidad, siendo inmediatamente codificada y transportada al laboratorio a una temperatura de $4{ }^{\circ} \mathrm{C}$, una por vez y en diferentes días entre los meses de enero a marzo de 2008. A todas las muestras de leche se les hizo el análisis de residuos de antibióticos $\beta$-lactámicos y de tetraciclinas por duplicado.

De acuerdo a las indicaciones de la empresa comercializadora, se homogeniza la muestra de leche y se vierte en el tubo de ensayo empleando la pipeta que incorpora el kit, aproximadamente $450 \pm 50 \mu \mathrm{L}$ de muestra, agitando la mezcla hasta disolver el botón reactivo que contiene el tubo de ensayo. Se incuba el tubo y el dispositivo del instrumento a $45 \pm 5{ }^{\circ} \mathrm{C}$ por cinco minutos (kit para $\beta$-lactámicos ó kit para tetraciclinas).

Concluida la incubación se añade el contenido del tubo sobre el pocillo de prueba del snap, observando la trayectoria hasta el círculo de activación y cuando éste desaparece, se presiona el activador hasta ajustarlo en el cuerpo del snap.

Se considera resultado positivo cuando el área de la muestra es más clara que el área control y como negativo cuando el área de la muestra es más oscura o de igual color que el área control.

El kit para detectar residuos de antibióticos $ß$ lactámicos en leche cruda tiene el siguiente nivel de sensibilidad en ppb: bencilpenicilina $\mathrm{G}(3,0)$, amoxicilina $(7,3)$, ampicilina $(5,8)$, ceftiofur $(5,4)$ y cefapirina $(11,7)$ en forma individual o en mezcla; siendo el nivel de tolerancia ó de seguridad, según la Food and Drug Administration (FDA) para amoxicilina y ampicilina 10 ppb, ceftiofur $50 \mathrm{ppb}$, cefapirina $20 \mathrm{ppb}$ y de penicilina G 5 ppb.

El nivel de sensibilidad que detecta el kit para residuos de tetraciclinas en forma individual o en mezcla, en ppb, es el siguiente: tetraciclinas (50), clortetraciclina (100) y oxitetraciclina (50).

\section{RESULTADOS}

Se detectaron residuos de antibióticos $\beta$-lactámicos en 16 de las 40 muestras estudiadas, lo que equivale al $40 \%$ del total de las muestras de leche cruda, y no se detectó residuos de tetraciclinas. 


\section{DISCUSIÓN}

Los resultados obtenidos son comparables a los valores elevados $(36,5$ y $50 \%)$ reportados por otros investigadores en la detección de $\beta$-lactámicos en leche cruda y pasteurizada ${ }^{(10)}$. Los ganaderos estarían utilizando antibióticos de espectro dominante sobre bacterias gram positivas de comportamiento tiempodependiente como los $\beta$-lactámicos, con extensión a bacterias gram negativas y concentración-dependiente, si es el caso de la amoxicilina, que también podría estar presente en la mezcla de residuos ${ }^{(1)}$, lo cual concuerda con Kang et al. ${ }^{(12)}$, quienes en su investigación hallaron que los $\beta$-lactámicos eran antibióticos que mostraban la mayor frecuencia de uso para el tratamiento de mastitis.

Por otro lado, se requiere proponer un adecuado programa de control a nivel de los productores, diagnosticar la magnitud y volumen del problema de los comercializadores de antibióticos de uso veterinario, de las instituciones encargadas de la regulación y vigilancia de la calidad e inocuidad de los alimentos a nivel nacional y regional, normar el descarte de leche con residuos de antibióticos a fin de que sea transformada para uso no alimentario, considerar el pago de estímulo a los productores de leche sin antibióticos, controlar la mastitis, capacitar constantemente en el tema a los ganaderos y empresas procesadoras, acabando con la mala práctica de enviar leche con residuos de antibióticos al procesamiento a alta temperatura ${ }^{(6)}$, y a los expendios de leche cruda de los mercados de abasto.

El método detectó la presencia individual o en mezcla de residuos de ampicilina, amoxicilina, bencilpenicilina G y ceftiofur, a diferencia del método de disco de Bacillus stearothermophilus modificado, que este no tiene la capacidad de distinguir ceftiofur de los otros antibióticos citados ${ }^{(13)}$, siendo además tan sensible como el método por biosensor para $\beta$-lactámicos ${ }^{(14)}$. El nivel de falsos positivos del kit para $\beta$-lactámicos es bastante reducido, atribuyéndose este error a la presencia de inhibidores naturales en la leche cruda, lo cual fue solucionado con el calentamiento de la muestra entre 90 y $100{ }^{\circ} \mathrm{C}$ por 5 minutos, tratamiento que no tiene influencia en muestras positivas.

La confirmación de los casos positivos, obtenidos en el presente trabajo de investigación en leche cruda, podría ser desarrollada mediante el método de cromatografía líquida de alta performance seguida de espectrometría de masa en tándem, empleando para la extracción acetonitrilo seguido de una columna en fase reversa. La metodología ha sido validada por la FDA para $\beta$-lactámicos ${ }^{(15)}$ y en la confirmación rápida de tetraciclina se ha probado con éxito una metodología semejante en muestras de carne de pollo y bovino con agua a $7 \mathrm{O}^{\circ} \mathrm{C}$ como solución extrayente, seguida de cromatografía líquida/espectrometría de masa en tándem equipada con una fuente electrospray de iones ${ }^{(16)}$.

El hallazgo de muestras positivas nos indican que el tratamiento de infecciones en el ganado así como la aplicación de antibióticos por diferentes causas en el establo, se estaría focalizando actualmente en los $\beta$-lactámicos; hecho que puede ayudar a dirigir políticas de legislación, regulación y capacitación, ya que no se detectó presencia de residuos de tetraciclinas en ninguna de las muestras analizadas.

La existencia de residuos de antibióticos en leche cruda permite entrever que, además de la regulación, es necesario mantener la vigilancia constante, empleando métodos altamente sensibles de presunción, confirmación y cuantificación, con valores límite permitidos por la FDA o la European Medicine Agency (EMEA).

\section{CONCLUSIONES}

Se encontró $40 \%$ de muestras con resultado positivo para residuos de $\beta$-lactámicos en leche cruda. No se registró resultado positivo al analizar tetraciclinas.

Los resultados hacen evidente la necesidad de revisar la norma nacional ${ }^{(16)}$, por ser de vital importancia para la salud de la población, especialmente del segmento que padece alergias por ser el más vulnerable.

\section{REFERENCIAS BIBLIOGRÁFICAS}

1. Anadón A. Antibióticos de uso veterinario y su relación con la seguridad alimentaria y salud pública. En: Real Academia de Ciencias Veterinarias; 2007 Jul 10; España. Disponible en www.racve.es/actividades/antibioticos

2. Koolman J, Rhöm K. Bioquímica. $3^{\underline{a}}$ ed.: Editorial Médica Panamericana, Madrid, 2004.

3. Goodman y Gilman. Bases Farmacológicas de la Terapéutica. 11⿳⺈ ed. Editorial Mc Graw Hill. NY, 2007.

4. Kempe M and Verachtert B. Cartridges with molecularly imprinted recognition elements for antibiotic residues monitoring in milk cream. Pure and applied Biochemistry, Lunds Universitét Centre for Chemistry and Chemical Engineering Getingevagen, Lund Sweden, 2000; pp: 1-10.

5. Bogialli S, Di Corcia A, Laganà A, Mastrantoni V, and Segi M. A simple and rapid confirmatory assay for analyzing antibiotic residues of the macrolide class and lincomycin in bovine milk and yoghurt; hot water extraction 
followed by liquid chromatography/tandem mass spectrometry. Rapid commun mass spectrom, 2007; 21 (2): 237-46.

6. Carreto L. Impacto de la presencia de antibióticos en leche. Procedente del $5^{\mathbf{0}}$ Taller Panamericano de Laboratorios Lácteos; Nov. 2005 1-5; Colonia Suiza, Montevideo.

7. AOAC. Antibiotics in milk (Bacillus stearothermophilus qualitative field disc assay). In: Official Method of Analysis, AOAC International, Gaithersburg, Maryland, USA, 2000.

8. Clark S, Turnipseed S, Madson M, Hurlbut J, Kuck L and Sofos J. Confirmation of sulfa methiazole and sulfadimethoxine residues in condenser milk and soft cheese products by liquid chromatography/tandem mass spectrometry. J. AOAC Int. 2005; 88(3): 736-43.

9. NTP 202.112. Leche y productos lácteos. Leche cruda. Muestreo de productos lácteos. Instrucción general. $\mathbf{1}^{\underline{a}}$ ed. Lima, 1998.

10. Khaskhely R, Malik M, Arain A, Soomro A., Arain H. Detection of $\beta$-lactam antibiotic residues in market milk. Pakistan J. Nut. 2008; 7(5): 682-685.

11. Ramírez A, Gutiérrez R, González C, Escobar I, Castro G, et al. Detección de antibióticos en leche comercializada en la ciudad de Méjico. Rev. Salud Anim. 2001; 23 (1): 37-41.

12. Kang J, Jin J, Kondo F. False positive outcome and drug residue in milk samples over withdrawal times. J. Dairy Sci. 2005; 88: 908-913.
13. Gilbertson T, Mejeur R, Yein F, Jaglan S. Modified Microbiological method for the screening of antibiotics in milk. J. Dairy Sci. May 1995; 78(5): 1032-8.

14. Gustavsson E, Sternesjö A. Biosensor analysis of blactams in milk: comparison with microbiological, immunological, and receptor-based screening methods. J. AOAC Int. May-Jun 2004; 87(3): 614-620.

15. Holstege D, Puschner B, Whitehead G, Galey F. Screening and mass spectral confirmation of lactam antibiotic residues in milk using LC-MS/MS. J. Agric. Food Chem. 2002; 50(2): 406-411.

16. NTP 202.001. Leche y productos lácteos. Leche cruda. Requisitos. 4 $4^{\mathrm{a}}$ ed. 2003.

Manuscrito recibido el: 30/11/2009

Aceptado para su publicación el: 23/02/2010

\section{Correspondencia:}

Nombre: Gerardo Gamarra Ballena / Elena Benavides Rivera

Dirección: Av. Antúnez de Mayolo N. 1095 - Urb. Mercurio - Los Olivos - Lima e-mail: elenabenavidesr@gmail.com 